\title{
Estimating maximum global land surface wind power extractability and associated climatic consequences
}

\author{
L. M. Miller ${ }^{1,2}$, F. Gans ${ }^{1}$, and A. Kleidon ${ }^{1}$ \\ ${ }^{1}$ Max Planck Institute for Biogeochemistry, Jena, Germany \\ ${ }^{2}$ International Max-Planck Research School for Earth System Modeling, Hamburg, Germany \\ Received: 25 April 2010 - Published in Earth Syst. Dynam. Discuss.: 15 September 2010 \\ Revised: 4 February 2011 - Accepted: 7 February 2011 - Published: 11 February 2011
}

\begin{abstract}
The availability of wind power for renewable energy extraction is ultimately limited by how much kinetic energy is generated by natural processes within the Earth system and by fundamental limits of how much of the wind power can be extracted. Here we use these considerations to provide a maximum estimate of wind power availability over land. We use several different methods. First, we outline the processes associated with wind power generation and extraction with a simple power transfer hierarchy based on the assumption that available wind power will not geographically vary with increased extraction for an estimate of $68 \mathrm{TW}$. Second, we set up a simple momentum balance model to estimate maximum extractability which we then apply to reanalysis climate data, yielding an estimate of $21 \mathrm{TW}$. Third, we perform general circulation model simulations in which we extract different amounts of momentum from the atmospheric boundary layer to obtain a maximum estimate of how much power can be extracted, yielding 18-34 TW. These three methods consistently yield maximum estimates in the range of 18-68 TW and are notably less than recent estimates that claim abundant wind power availability. Furthermore, we show with the general circulation model simulations that some climatic effects at maximum wind power extraction are similar in magnitude to those associated with a doubling of atmospheric $\mathrm{CO}_{2}$. We conclude that in order to understand fundamental limits to renewable energy resources, as well as the impacts of their utilization, it is imperative to use a "topdown" thermodynamic Earth system perspective, rather than the more common "bottom-up" engineering approach.
\end{abstract}

Correspondence to: L. M. Miller (lmiller@bgc-jena.mpg.de)

\section{Introduction}

Several recent studies (Archer and Jacobson, 2005; Santa Maria and Jacobson, 2009; Lu et al., 2009; Jacobson and Archer, 2010a) propose that wind power can easily meet the current global human energy demand while also having negligible impacts on the Earth system. Archer and Jacobson (2005) quantified $72 \mathrm{TW}$ of wind power extraction potential over land utilizing only $13 \%$ of the most windy land areas. Lu et al. (2009) increased this land-based quantification to $125 \mathrm{TW}$ using an increased land area, larger wind turbines, and additional wind velocity measurements. Even more recently, Jacobson and Archer (2010a) stated that should $11.5 \mathrm{TW}$ of wind turbine derived electricity sustain global power demand, “.... [the required wind turbine] power extraction at $100 \mathrm{~m}$ amounts to $<1 \%(11.5 \mathrm{TW} / 1700 \mathrm{TW})$ of the world's available wind power at $100 \mathrm{~m}$."

All of the above-mentioned studies neglect energy conservation, nearly imperceptible at smaller scales but critical when quantifying wind power potential at regional to global scales, as recently shown by Gans et al. (2010). The methodologies for calculating extractable wind power employed by these studies (Jacobson and Masters, 2001; Archer and Jacobson, 2003, 2005; Archer and Caldeira, 2009; Santa Maria and Jacobson, 2009; Lu et al., 2009; Jacobson and Delucchi, 2010) also differ significantly with those of Keith et al. (2004) and Wang and Prinn (2010) and should not be confused.

Combining wind turbine characteristics and wind velocity measurements is critical when estimating the potential electricity output of a proposed wind farm but the engineering focused "bottom-up" methodology does not allow the quantification of changes to global wind power availability

Published by Copernicus Publications on behalf of the European Geosciences Union. 
or climatic impacts directly resulting from wind power extraction. Previous very large-scale estimates, such as those utilizing large expanses of land (e.g. Archer and Jacobson, 2005) or the global atmospheric boundary layer (e.g. Santa Maria and Jacobson, 2009) for wind energy extraction cannot use the same methodology as small wind farm developments without resulting in overestimations.

Kinetic wind energy, and thereby extractable wind power, is not infinite. Here, we constrain our estimates by the total rate of kinetic wind energy generated in the Earth system (Lorenz, 1955; Gustavson, 1979; Kleidon, 2010). We use a simple back-of-the-envelope estimate to illustrate the natural Earth system process hierarchy that could result in wind power extractability from the atmospheric boundary layer. This process-based understanding is then extended with 2 different methods of increasing complexity, both based on fundamental limits of kinetic energy generation and extractability. From these differing methods, we can estimate a range of wind power extractability potentials over all nonglaciated land surfaces.

These estimates therefore represent a realistic range of the maximum wind power potential that cannot be exceeded by improving wind turbine technologies (e.g. increasing their height or blade length, capacity factor, between-turbine spacing) or wind velocity mapping methods while maintaining energy conservation. Inevitably, this removal of wind power from the Earth system must result in climatic impacts, shown here to be linearly proportional to the amount of wind power extraction.

\section{Estimation of wind power availability over land}

Approximately 900 TW of kinetic wind energy is currently generated and dissipated in the global atmosphere (Lorenz, $1955)$ - this is based on theory and supporting observations (Peixoto and Oort, 1992). Thermodynamic derivations show that this rate of wind power generation is the maximum rate achievable by the Earth System given present-day radiative forcing gradients, demonstrated by simple theoretical considerations (Lorenz, 1960), box models (Paltridge, 1978; Lorenz et al., 2001; Kleidon, 2010), and general circulation models (Kleidon et al., 2003, 2006). Of the total wind power in the atmosphere, physics-based considerations fundamentally restrict the extraction potential of turbines to a decreased percentage of the initial flow (Lanchester, 1915; Betz, 1920). Using these ingredients, we derive 3 different estimates of wind power availability.

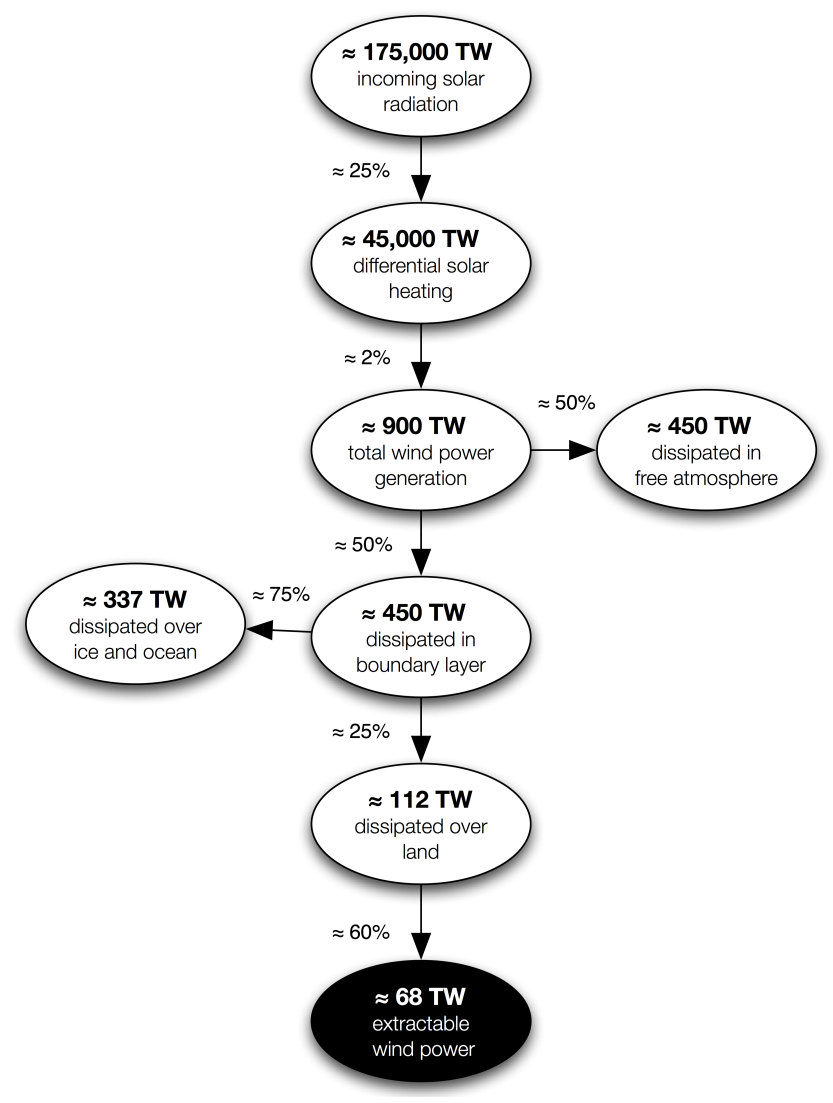

Fig. 1. The conversion processes between incoming solar radiation and extractable wind power over the land in the Earth system is shown. In this simplified framework, assuming a $100 \%$ conversion efficiency from mechanical power to electrical power, a maximum of $68 \mathrm{TW}$ of electricity can be produced from wind power extraction from the atmospheric boundary layer over all non-glaciated land surfaces.

\subsection{How to conceptualize the process hierarchy - a back-of-the-envelope estimate}

A conceptualization of the interacting processes that could result in wind power extractability in the atmospheric boundary layer is shown in Fig. 1 and briefly outlined as follows:

1. $175000 T W \approx$ incoming solar radiation at the top of the atmosphere

2. $45000 T W \approx 25 \%$ of incoming solar radiation, differential solar heating results in atmospheric pressure differences which sets the air into motion, a process that is currently operating at its maximum rate of conversion (Lorenz, 1960)

3. $900 T W \approx 2 \%$ of differential solar heating, total wind power generation rate in the global atmosphere (Lorenz, $1955)$ is the upper limit available for wind power extraction (Gustavson, 1979) 
4. $450 T W \approx 50 \%$ of total generated wind power is dissipated in the atmospheric boundary layer (Peixoto and Oort, 1992)

5. $112 \mathrm{TW} \approx 25 \%$ of the global land surface is nonglaciated land so assuming dissipated kinetic energy is equally distributed globally, this percentage of kinetic wind energy is most accessible for extraction

6. $68 \mathrm{TW} \approx 60 \%$ at most of the wind power extraction rate can be converted to mechanical power (Lanchester, 1915; Betz, 1920)

Note that this process-based understanding is completely independent of wind velocity measurements and wind turbine characteristics (e.g. hub-height, aerodynamic efficiency, rotor diameter). The maximum land-based wind power extractability is not dependent on current engineering or technological limitations, but is instead completely dependent on wind power generation rates (Gustavson, 1979) and the unavoidable competition between wind power extraction and dissipation by natural processes such as turbulence. This estimate also includes numerous simplifications compared to the Earth system. For example, it assumes that wind power can be extracted where kinetic wind energy is dissipated. The introduction of large-scale wind turbines would certainly alter the global patterns of atmospheric boundary layer dissipation. It also does not consider the contribution of momentum from higher-altitudes (Calaf et al., 2010) or the availability of extractable kinetic energy that was generated over the oceans. Finally, there is no feedback on the generation rate of kinetic wind energy resulting from wind power extraction.

Given these stated assumptions, the back-of-the-envelope estimate is only applicable as a first-order approximation of the processes related to wind power extraction from the atmospheric boundary layer. Its true benefit lies in its transparency, making it immediately apparent that much less than the generation rate of kinetic wind energy in the Earth system is available for extraction, regardless of the technology, as well as being based on very simple straightforward assumptions.

\subsection{Simple momentum model with reanalysis wind data}

A simple momentum balance model was developed to refine the back-of-the-envelope estimate of maximum wind power extractability. To establish the limit of maximum extraction, we consider the momentum balance of the boundary layer in steady state as:

$$
\frac{d(m v)}{d t}=F_{\text {acc }}-F_{\text {fric }}-M=0
$$

where $m v$ represents atmospheric momentum, $F_{\text {acc }}$ is the rate of momentum generation by an acceleration force, $F_{\text {fric }}=$ $k \cdot v^{2}$ is the frictional force resulting in boundary layer turbulence with $k$ being a friction coefficient $(\mathrm{kg} \mathrm{m})$ and $v$ being the mean 1958-2001 European Centre for Medium Range Forecasting (ECMWF) ERA-40 10-m wind velocity $\left(0.7457 \mathrm{~m} \mathrm{~s}^{-1}\right)$, and $M$ is the rate of momentum extraction by wind turbines. $F_{\text {acc }}\left(1.1918 \times 10^{14} N\right)$ is assumed to be constant, constrained by thermodynamic limits and currently operating at the maximum rate achievable as discussed by thermodynamic arguments (Paltridge, 1978; Lorenz et al., 2001; Kleidon, 2010) as well as climate model simulations (Kleidon et al., 2003, 2006).

The mean wind flow $v$ is then given by:

$v=\left(\left(F_{\text {acc }}-M\right) / k\right)^{1 / 2}$

The wind power in the boundary layer $P_{\text {tot }}$ is given by:

$P_{\text {tot }}=F_{\text {acc }} \cdot v$

This power is partitioned into dissipation by natural boundary layer turbulence $D_{\mathrm{n}}$ and power extraction $P_{\mathrm{ext}}(M)$ by wind turbines:

$P_{\mathrm{tot}}=D_{\mathrm{n}}+P_{\mathrm{ext}}(M)$

The expressions for these terms are:

$D_{\mathrm{n}}=F_{\text {fric }} \cdot v=k \cdot v^{3}$

and

$P(M)=M \cdot v=M \cdot\left(\left(F_{\text {acc }}-M\right) / k\right)^{1 / 2}$

The maximum power extraction from the system is obtained by:

$\frac{d P_{\mathrm{ext}}}{d M}=0$

yielding an optimum value of extracted momentum $M_{\mathrm{opti}}$ :

$M_{\text {opti }}=2 / 3 \cdot F_{\text {acc }}$

The associated maximum power extracted is:

$P_{\text {ext } \text { max }}=2 \cdot(1 / 3)^{(3 / 2)} \cdot P_{\text {tot }}(M=0)$

or about $38.5 \%$ of the original wind power in the absence of extraction. Of the extracted power, less than $60 \%$ of the wind power extracted from the atmospheric system is effectively converted to mechanical power while the rest of the extracted wind power is dissipated as wake turbulence (Lanchester, 1915; Betz, 1920; Garrett and Cummins, 2007).

We now use this estimated maximum efficiency of extraction and combine it with the wind power in the boundary layer as estimated from the ECMWF ERA-40 reanalysis climate data (ECMWF, 2004). We use the $u$ - and $v$-surface wind stress and $10-\mathrm{m} u$ - and $v$-wind velocity components to estimate natural dissipation $D$ in the atmospheric boundary layer: 


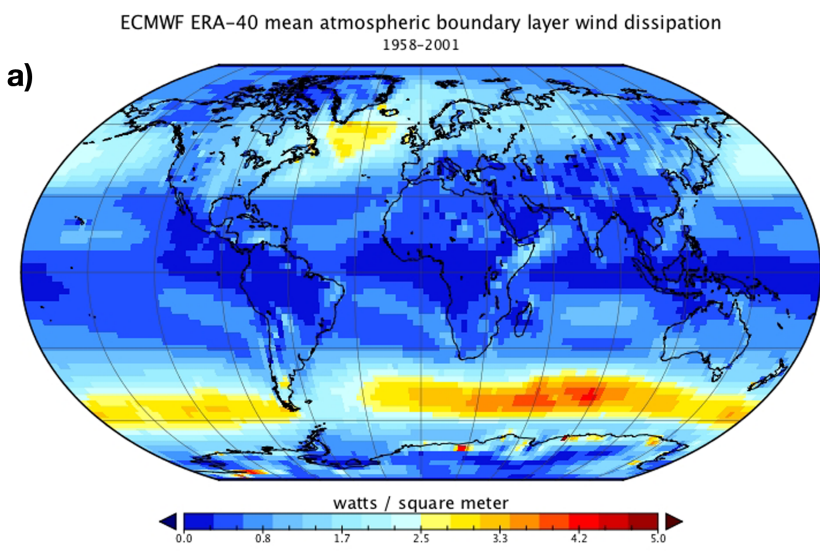

ECMWF ERA-40 mean atmospheric boundary layer wind dissipation over land

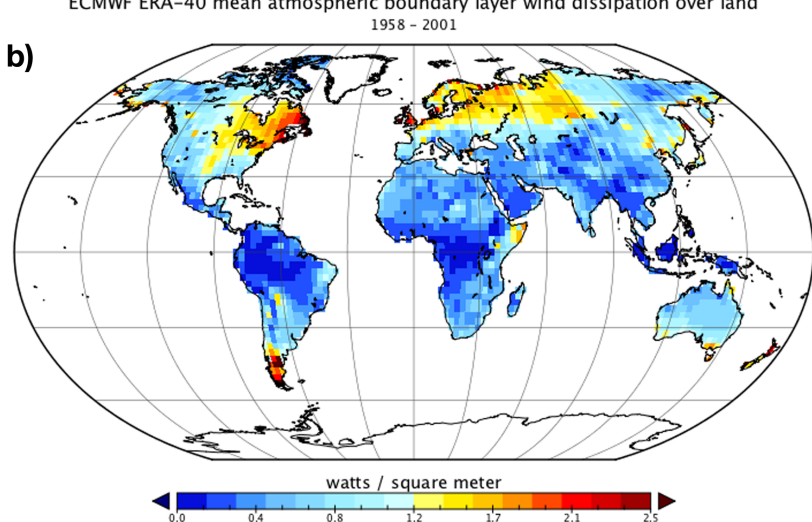

Fig. 2. Distribution of estimated boundary layer wind dissipation (a) globally and (b) over non-glaciated land as a proxy for wind power extractability from ECMWF ERA-40 reanalysis data.

$D=\tau \cdot v_{l}$

where $\tau$ is the wind stress and $v_{l}$ is the wind velocity. We find that for the period 1958-2001, a mean of 513 TW of wind energy is dissipated globally in the atmospheric boundary layer, most of which is dissipated over the southern ocean (Fig. 2). Of these 513 TW, 89 TW are dissipated over non-glaciated land surfaces that would be most easily accessible for wind turbine installations.

Using the simple momentum balance model and the estimated land-based dissipation of the ECMWF ERA-40 data results in a maximum extraction rate of $34 \mathrm{TW}$ from the initial $89 \mathrm{TW}$ of dissipation. Based on previously mentioned unavoidable inefficiencies (Lanchester, 1915; Betz, 1920; Garrett and Cummins, 2007) and a $100 \%$ conversion efficiency from mechanical to electrical power, a maximum of $21 \mathrm{TW}$ of electricity can be produced (Fig. 3). The simple momentum balance model also extends the back-of-theenvelope estimate by showing how an overall increase in momentum removal (natural drag + human extraction) corresponds to a decrease in boundary layer dissipation, with increased momentum removal beyond the maximum power

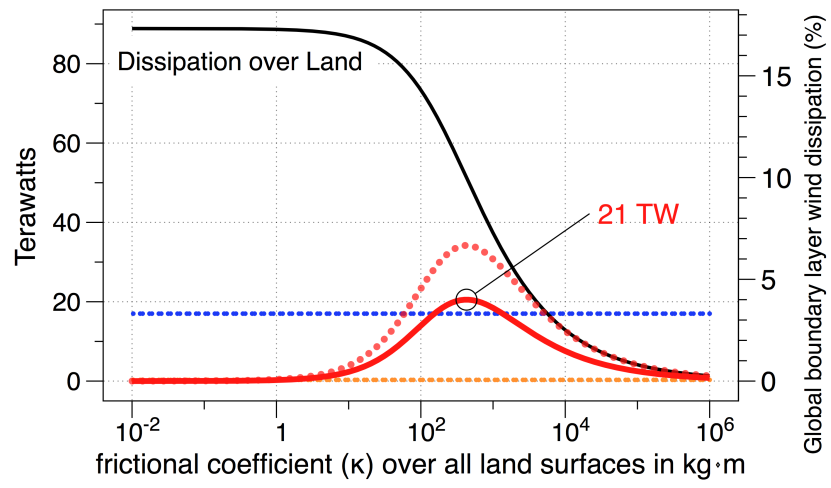

Fig. 3. The relationship between an increased frictional coefficient $(\kappa)$ to changes in wind dissipation over land (black line), extracted wind power (dashed red), and mechanical power that drives the wind turbine (solid red) is shown for the simple momentum balance model. For reference, the dashed blue horizontal line shows the estimated 17 TW of global energy demand in 2009 (EIA, 2009) and the dashed orange horizontal line indicates the estimated $0.03 \mathrm{TW}$ of global electricity production by wind turbines in 2008 (World Wind Energy Association, 2008).

extraction corresponding to a decrease in extracted power due to the reduced wind velocities.

\subsection{Climate model simulations}

In the third method, we use a global climate model of intermediate complexity (Fraedrich et al., 2005; Lunkeit et al., 2007) and a methodology similar to the one used by Keith et al. (2004) to implement the effects of wind turbines. The climate model consists of a low-resolution atmospheric general circulation model, a mixed-layer ocean model with prescribed ocean heat transport, interactive sea-ice model, a simple land surface model, and prescribed ice sheets. To quantify the variations resulting from model resolution, 4 different model configurations were utilized: T21 spectral resolution (5.6 $6^{\circ}$ longitude by $5.6^{\circ}$ latitude) and ten atmospheric levels, T21 spectral resolution with twenty atmospheric levels, T42 spectral resolution $\left(2.8^{\circ}\right.$ longitude by $2.8^{\circ}$ latitude) with ten atmospheric levels, and T42 spectral resolution with twenty atmospheric levels.

Boundary layer dissipation in the lowest model layer is parameterized by the commonly used surface drag parameterization of the form:

$F_{\text {drag }}=\rho\left(C_{\mathrm{n}}\left|\boldsymbol{v}_{\mathbf{l}}\right|+C_{\text {ext }}\left|\boldsymbol{v}_{\mathbf{l}}\right|\right) \cdot \boldsymbol{v}_{\mathbf{l}}$

where $\rho$ is the air density, $C_{\mathrm{n}}$ is the volumetric drag coefficient for natural turbulence (which depends on surface roughness and atmospheric stability among other factors), $\boldsymbol{v}_{\mathbf{l}}$ is the wind velocity, and $C_{\text {ext }}$ is the additional volumetric drag coefficient to simulate momentum extraction by wind turbines. This model's reference manual provides a more 
Table 1. Mean data values for ECMWF ERA-40 reanalysis data (1958-2001), T21 spectral resolution with 10 and 20 vertical layers (20 year mean), and T42 spectral resolution and 10 vertical layers and 20 vertical (20 year mean) is shown. The corresponding units are: global $=$ global atmospheric boundary layer dissipation in terawatts (TW), land = non-glaciated land atmospheric boundary layer dissipation in terawatts (TW), mean = mean of all data values in $\mathrm{W} \mathrm{m}^{-2}$, median $=$ median of all data values in $\mathrm{W} \mathrm{m}^{2}, \sigma=$ standard deviation of all data values, and count $=$ number of input data values.

\begin{tabular}{lcrcccr}
\hline data & global & land & mean & median & $\sigma$ & count \\
\hline ERA-40 & 513 & 89 & 1.06 & 0.77 & 0.82 & 10512 \\
T21,10 & 352 & 71 & 0.76 & 0.61 & 0.54 & 2048 \\
T21,20 & 352 & 71 & 0.76 & 0.60 & 0.55 & 2048 \\
T42,10 & 497 & 125 & 1.09 & 0.80 & 0.90 & 8192 \\
T42,20 & 496 & 126 & 1.09 & 0.80 & 0.91 & 8192 \\
\hline
\end{tabular}

detailed explanation of the drag parameterization (Lunkeit et al., 2007).

Natural dissipation by boundary layer turbulence $D$ is given by

$D=\rho C_{\mathrm{n}} v_{\mathrm{l}}^{3}$

while the extracted power by wind turbines is given by:

$P_{\text {ext }}=\rho C_{\text {ext }} \boldsymbol{v}_{\mathbf{l}}^{\mathbf{3}}$

A range of model simulations was conducted for different values of $C_{\text {ext }}$. The simulation with $C_{\text {ext }}=0.0$ represents the natural case in the absence of power extraction by wind turbines and is referred to as our control simulation. In total, 13 simulations were completed with different values of $C_{\text {ext }}=[0.0: 1.0]$ for each of the 4 model configurations. All simulations were conducted for 30 simulated years with the first 10 years discarded from the analysis to exclude spinup effects. As large drag coefficients (e.g. $C_{\text {ext }}=1.0$ ) greatly increase the atmospheric boundary layer depth, the lowest model layer influenced by $F_{\text {drag }}$ is referred to as the controlregion atmospheric boundary layer and is the only vertical level available for potential wind power extraction.

To compare the control simulations of the general circulation model and the estimated atmospheric boundary layer dissipation of the ECMWF ERA-40 reanalysis data, the mean values of each grid cell value in the boundary layer dataset were compared. As shown in Table 1, the T42 simulations correspond to the ECMWF ERA-40 reanalysis data more closely than the T21 simulations. This general interpretation is further reinforced by comparing the histograms as shown in Fig. 4. Note the absence of mean dissipation values $>3 \mathrm{~W} \mathrm{~m}^{-2}$ in the T21 simulation (Fig. 4a) but the presence of these values in the T42 simulation (Fig. 4b). Although the T42 simulation land dissipation is larger than the
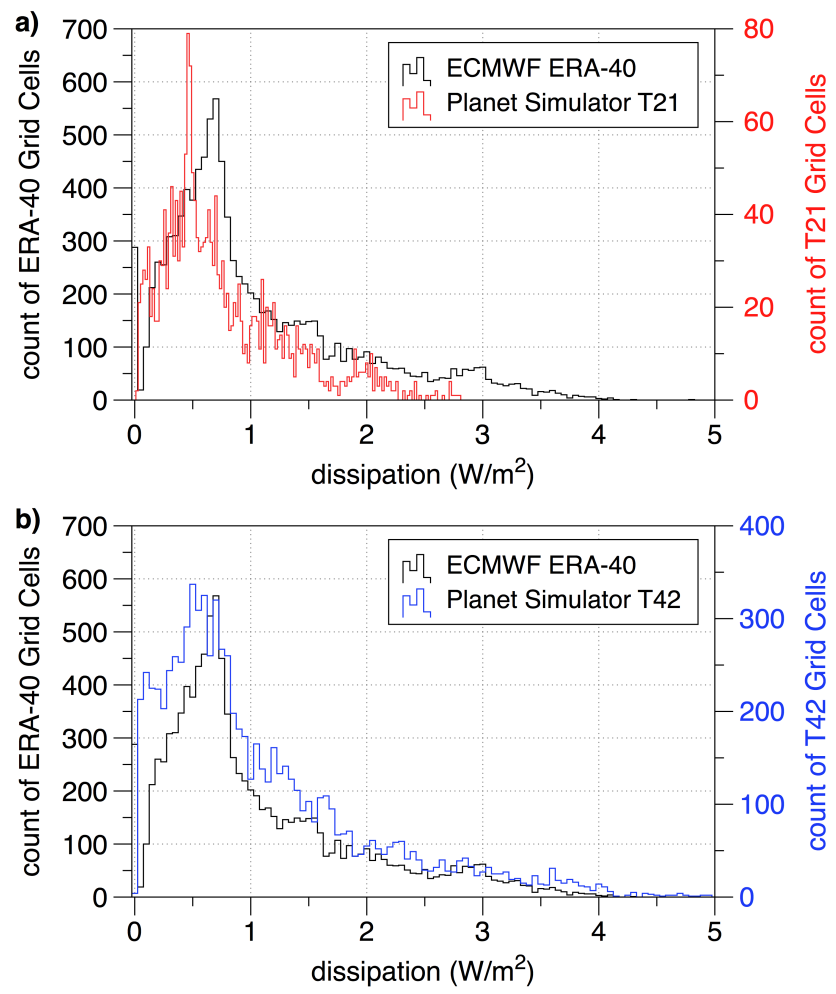

Fig. 4. Global mean dissipation values for (a) ERA-40 and a T21 10-vertical layer simulation and (b) ERA-40 and T42 10vertical layer simulation.

ECMWF ERA-40 reanalysis data, the general agreement between the statistics (Table 1) and histograms (Fig. 4b) indicates that the T42 model resolution and ERA-40 based estimate from the previous section are similar, providing scientific validity with both resulting estimates. Their relative discrepancy from the T21 simulations can in part be attributed to that model paramertization's poor representation of topography due to less spatial resolution.

The sensitivity of wind power extraction over land is shown in Fig. 5. It is very similar to the simple estimate of Fig. 3. Different general circulation model configurations result in different estimates. For the T21 simulations with 10 vertical layers, we find a maximum of $\approx 18 \mathrm{TW}$ of mechanical power over all non-glaciated land surfaces in the boundary layer in comparison to the $71 \mathrm{TW}$ of boundary layer dissipation in the control simulation. For the T42 simulations with 10 vertical layers, we find a maximum of $\approx 34 \mathrm{TW}$ of mechanical power over all non-glaciated land surfaces in the boundary layer in comparison to the $125 \mathrm{TW}$ of boundary layer dissipation in the control simulation.

Although the estimated ECMWF ERA-40 dissipation values and the T42 simulations were previously shown to be similar, only the non-glaciated land dissipation (89 TW) was used in the simple momentum balance model. As such, we would expect the exchange of momentum between land and 

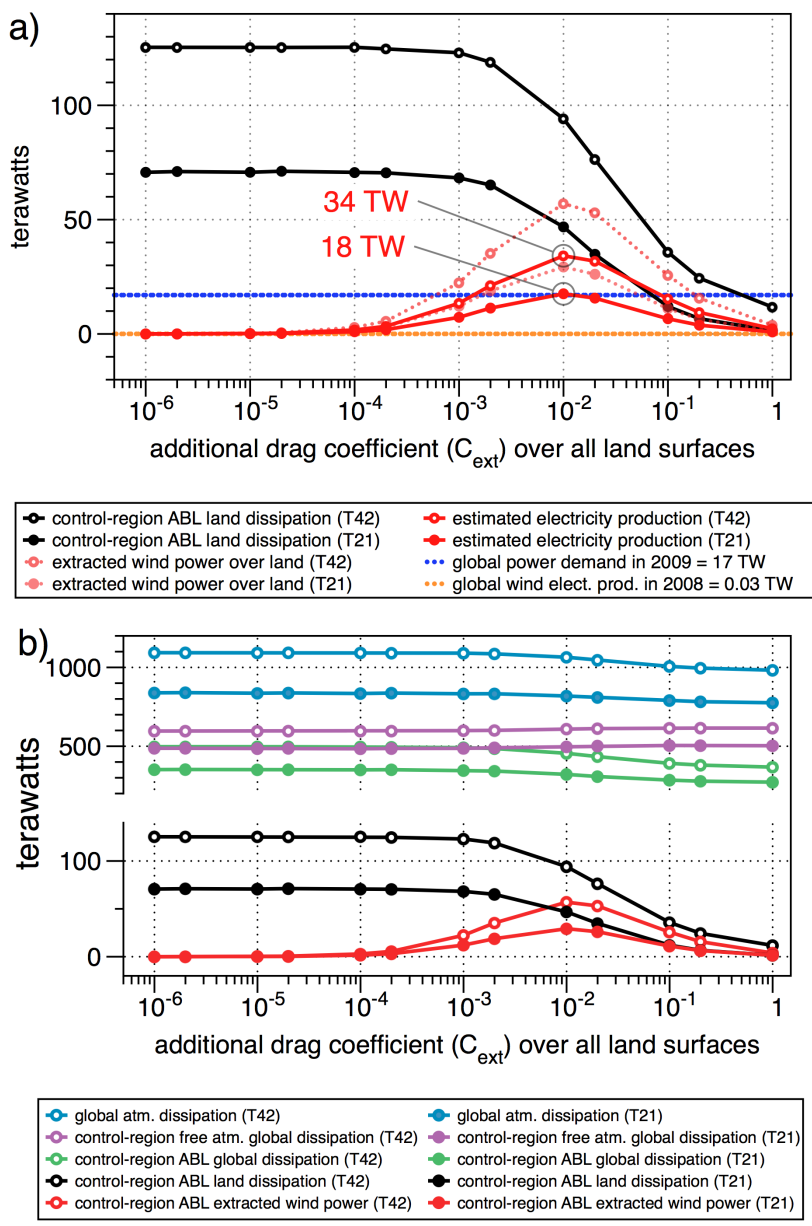

Fig. 5. In (a) sensitivity analysis between an increased drag coefficient $\left(C_{\text {ext }}\right)$ over all non-glaciated land surfaces and the corresponding impacts to atmospheric boundary layer wind dissipation over land, extracted wind power (additional turbulence + power extraction), and mechanical wind power for the T42 (open circles) and T21 (closed circles) simulations with 10 vertical layers. Controlregion corresponds to the volumetric region of the atmosphere in the control simulation, as increased drag coefficients eventually result in a new vertical compartmentalization of atmospheric boundary layer and free atmosphere dissipation. For reference, the dashed blue horizontal line shows the estimated $17 \mathrm{TW}$ of global energy demand in 2009 (EIA, 2009) and the dashed orange horizontal line indicates the estimated $0.03 \mathrm{TW}$ of global electricity production by wind turbines in 2008 (World Wind Energy Association, 2008).

In (b), the same sensitivity analysis is shown but illustrating changes to the global atmospheric dissipation, control-region free atmosphere dissipation, control-region global atmospheric boundary layer dissipation, and control-region atmospheric boundary layer dissipation over land.

ocean that is present in the general circulation model but absent in the simple momentum balance model to result in a higher maximum extractable power for the T42 simulations which did occur. The variation of initial dissipation rates between the general circulation model simulations and the
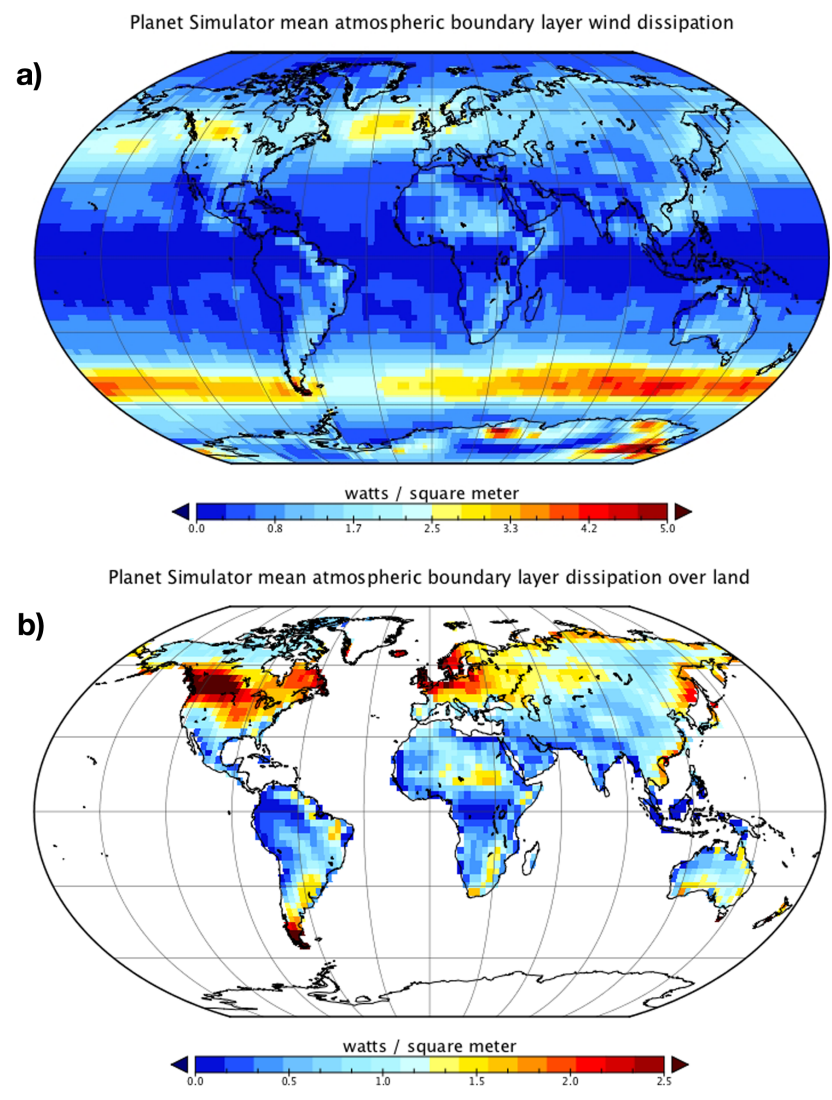

Fig. 6. Distribution of boundary layer wind dissipation (a) globally and (b) over non-glaciated land as a proxy for wind power extractability simulated by a general circulation mode at T42 resolution and 10 vertical layers.

ERA-40 estimate may also explain the range of extracted mechanical power estimates. For comparison purposes, the mean dissipation for control conditions with a T42 spectral resolution and 10 vertical layers is shown in (Fig. 6).

\section{Climatic impacts from wind power extraction}

Global atmospheric motion will be affected by the extraction of momentum by large-scale wind turbine development. It has been previously suggested that the global human energy demand (17 TW in 2009; EIA, 2009) could be easily accounted for by large-scale wind power development (Archer and Jacobson, 2005; Archer and Caldeira, 2009; Santa Maria and Jacobson, 2009; Lu et al., 2009). In stark contrast, our estimates suggest that $17 \mathrm{TW}$ of wind power derived electricity would represent $\approx 50-95 \%$ of the maximum land-based wind power possible with significant climate effects. We use the climate model simulations of Sect. 2.3 to demonstrate these climate effects.

The control simulation was initially compared to an identical control simulation to estimate the variability within 

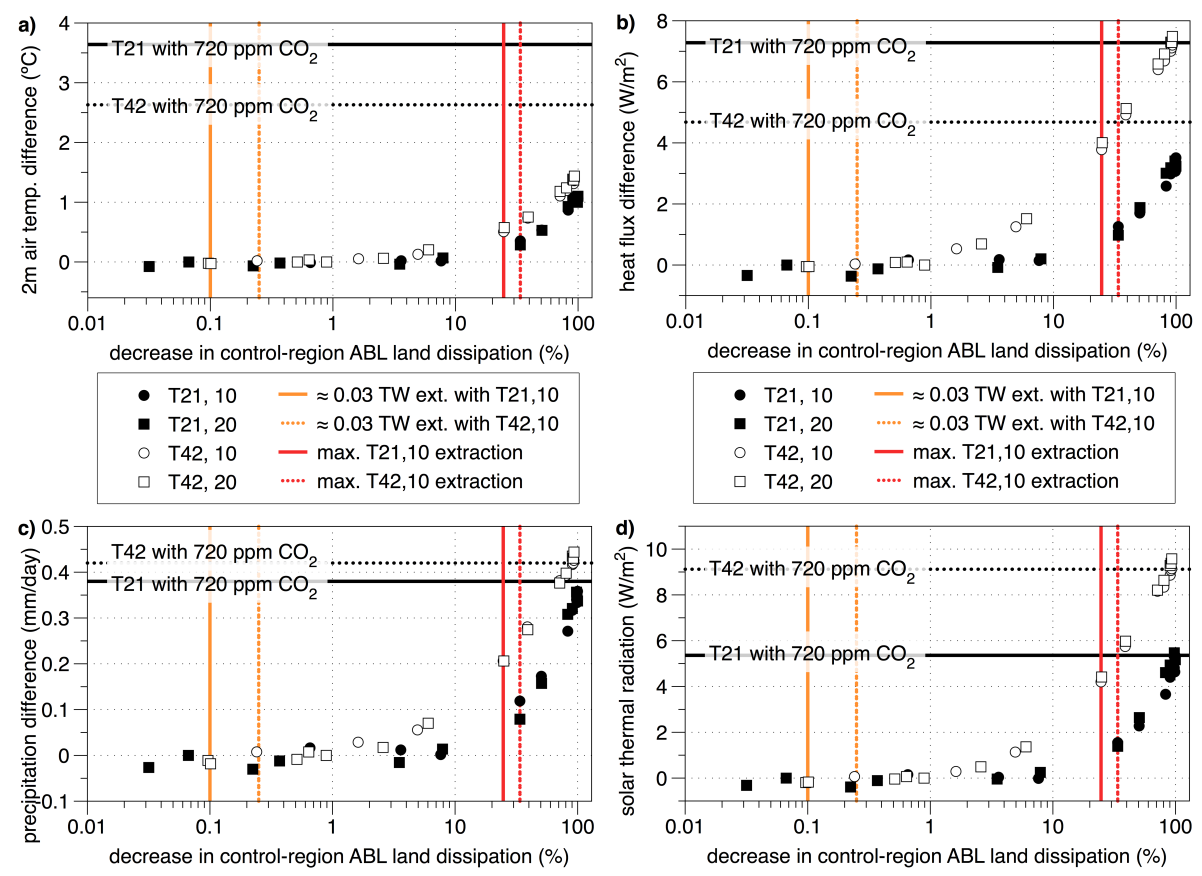

Fig. 7. A simulated sensitivity analysis showing absolute differences in climatic variables over all non-glaciated land for (a) 2-m air temperature, (b) sensible + latent heat flux, (c) precipitation, and (d) surface thermal radiation, resulting from increasing land-based wind power extraction compared to the respective model configuration control simulation. For comparison, simulations with an atmospheric $\mathrm{CO}_{2}$ concentration of $720 \mathrm{ppm}$ are shown for a T21 simulation with 10 vertical levels (horizontal solid black line) and a T42 simulation with 10 vertical levels (horizontal dashed black line). For reference, the maximum wind power extraction (vertical red lines) and estimated $0.03 \mathrm{TW}$ of electricity production in 2008 (World Wind Energy Association, 2008) from the general circulation model configurations (vertical orange lines) is also shown. The climatic differences are shown in relation to the decrease in control-region atmospheric boundary layer (ABL) land dissipation estimated by the respective model configuration.

the climate model for the analyzed climatic variables and as such, there was no need for error estimation within the 52 simulations. To compare the magnitude of the climatic effects, we perform an additional model simulation using an identical control setup with a doubled atmospheric $\mathrm{CO}_{2}$ concentration of $720 \mathrm{ppm}$. Area-weighted mean land values only changed slightly at the maximum wind power extraction $\left(C_{\text {ext }}=0.01\right)$ and the sensitivity to a doubled $\mathrm{CO}_{2}$ concentration shows a typical magnitude of change $\left(\mathrm{CO}_{2}=720 \mathrm{ppm}\right)$ as shown in Table 2. This is to be expected since the primary cause for the expected climatic changes from wind power extraction (the decrease in atmospheric mixing and transport) are much less directly linked to surface temperature change than direct changes in radiative forcing due to elevated $\mathrm{CO}_{2}$ concentrations.

To identify resulting climatic impacts, we take the areaweighted mean of the absolute value differences for monthly climatological means for 20 simulation years for all nonglaciated land grid points as: $\sum_{n}^{1}\left|x_{\text {simulation }}-x_{\text {control }}\right|$, where $x$ is the climatic variable under consideration. Values reflect the climatic impacts resulting from the decrease in atmospheric boundary layer dissipation over land, at the maximum wind power extraction by $24.7 \%$ in the $\mathrm{T} 21,10$ vertical level simulation and $33.8 \%$ in the T42, 10 vertical level simulation (Fig. 5). Absolute differences do not identify if a land point is warmer or wetter than the control simulation, but rather focus on how monthly climatic variables differ. Figure 7 shows the linear sensitivity response of 2-m air temperature, heat fluxes, precipitation, and surface thermal radiation to increases in momentum extraction and associated decrease in the control-region atmospheric boundary layer dissipation over land.

Previous studies have shown changes in climatic variables with wind power extraction (Keith et al., 2004; Roy and Pacala, 2004; Kirk-Davidoff and Keith, 2008; Barrie and Kirk-Davidoff, 2010; Wang and Prinn, 2010), but this study directly relates changes in boundary layer dissipation to absolute differences in climate. As shown in Fig. 7, the magnitude change of heat flux and precipitation for the maximum wind power extraction simulations are similar in value to the $720 \mathrm{ppm} \mathrm{CO}_{2}$ simulations. Maximum wind power extraction over non-glaciated land (Fig. 8) also results in changes in 2-m air temperature, convective precipitation rates, and incoming solar radiation at the surface as shown in Fig. 9.

These climatic impacts are the result of increased turbulence and entrainment of higher-altitude air from the simulated wind turbines. This higher-altitude air has a higher 
Table 2. The area-weighted mean climatic variables of all nonglaciated land points for the control simulation $\left(C_{\mathrm{ext}}=0.00\right.$ and $\mathrm{CO}_{2}=360 \mathrm{ppm}$ ), $C_{\text {ext }}=0.01$ for maximum wind power extraction, and an atmospheric $\mathrm{CO}_{2}=720 \mathrm{ppm}$ simulation are shown. The associated climatic variables have the following units: temperature in ${ }^{\circ} \mathrm{C}$, heat flux (latent + sensible) in $\mathrm{W} \mathrm{m}^{-2}$, precipitation in $\mathrm{mm} \mathrm{day}^{-1}$, and surface thermal radiation in $\mathrm{W} \mathrm{m}^{2}$.

\begin{tabular}{lccrrc}
\hline resol. & $C_{\text {ext }}$ & 2 m air temp & heat flux & precip. & surf rad. \\
\hline T21,10 & 0.00 & 16.50 & 97.93 & 3.06 & 77.70 \\
T21,20 & 0.00 & 16.49 & 98.17 & 3.08 & 77.16 \\
T21,10 & 0.01 & 16.93 & 96.96 & 2.99 & 79.13 \\
T21,20 & 0.01 & 16.92 & 97.20 & 3.02 & 78.69 \\
\hline T42,10 & 0.00 & 13.95 & 70.46 & 1.63 & 76.46 \\
T42,20 & 0.00 & 13.97 & 70.55 & 1.66 & 76.21 \\
T42,10 & 0.01 & 14.32 & 70.45 & 1.63 & 77.77 \\
T42,20 & 0.01 & 14.32 & 70.52 & 1.65 & 77.66 \\
\hline resol. & $C O_{2}$ & $2 \mathrm{~m}$ air temp & heat flux & precip. & surf rad. \\
\hline T21,10 & 360 & 16.50 & 97.93 & 3.06 & 77.70 \\
T21,20 & 360 & 16.49 & 98.17 & 3.08 & 77.16 \\
T21,10 & 720 & 20.39 & 105.06 & 3.20 & 72.66 \\
T21,20 & 720 & 20.35 & 104.63 & 3.20 & 73.58 \\
\hline T42,10 & 360 & 13.95 & 70.46 & 1.63 & 76.46 \\
T42,20 & 360 & 13.97 & 70.55 & 1.66 & 76.21 \\
T42,10 & 720 & 15.63 & 95.27 & 2.79 & 78.98 \\
T42,20 & 720 & 15.66 & 95.63 & 2.78 & 78.59 \\
\hline
\end{tabular}

potential temperature and when mixed with the air near the surface, results in a temperature increase. The increased turbulent mixing of the atmosphere from large-scale wind power extraction is also associated with changes in convective precipitation and solar radiation at the surface. These climatic impact dynamics are similar to those previously illustrated by Kirk-Davidoff and Keith (2008).

\section{Discussion}

\subsection{Limitations}

Our results show how the generation rate of kinetic wind energy in the atmosphere and thermodynamic constraints of power extraction ultimately limit wind power extractability. This is consistent with previous supporting research that states at the large scale:

1. conversion efficiencies from incoming solar radiation to atmospheric motion are currently maximized to presentday radiative forcing (Lorenz, 1960; Paltridge, 1978)

2. the maximized conversion rate suggests $\approx 900 \mathrm{TW}$ of atmospheric kinetic energy is generated and dissipated in the Earth system (Peixoto and Oort, 1992; Kleidon, 2010)

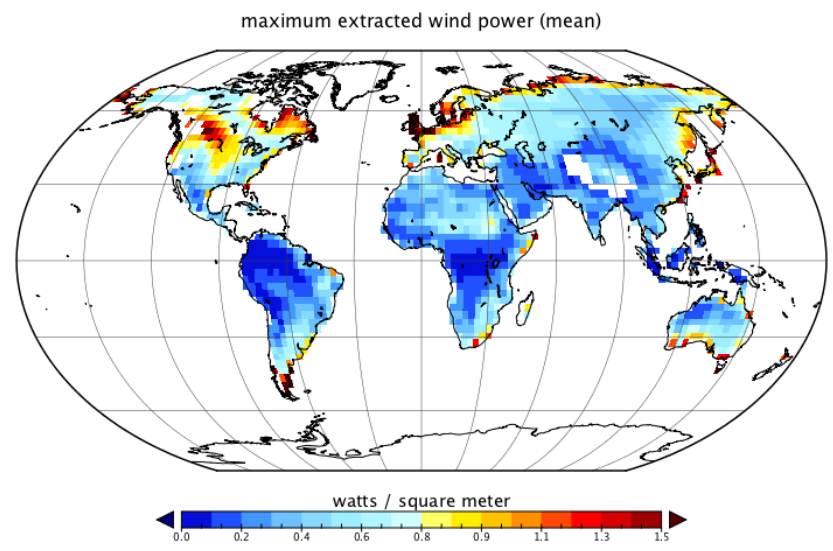

Fig. 8. The maximum wind power extraction at T42 resolution and 10 vertical levels for a total extraction of $34 \mathrm{TW}$ of mechanical power. Each non-glaciated land grid point has been parameterized with an additional drag coefficient $\left(C_{\text {ext }}=0.01\right)$. Note the influence of the large-scale circulation on large-scale extractable wind power, also noted in Barrie and Kirk-Davidoff (2010).

3. Earth's kinetic wind energy generation rate is the unattainable upper-bound for any kinetic wind energy extraction technology (Gustavson, 1979)

4. perturbations to the system will decrease the conversion efficiency from solar radiation to atmospheric motion (Lucarini et al., 2010; Hernández-Deckers and von Storch, 2010), with wind turbines being one example of an atmospheric perturbation

5. large-scale wind power extraction will result in climatic impacts (Keith et al., 2004; Roy and Pacala, 2004; KirkDavidoff and Keith, 2008; Barrie and Kirk-Davidoff, 2010; Wang and Prinn, 2010; Kirk-Davidoff , 2010)

Points 1-3 are reproduced in our simple back-of-theenvelope estimate, a simple momentum balance model, and a range of model resolutions with a general circulation model of intermediate complexity. Taken together, our estimates range from 18-68 TW and are significantly less than the $\approx 900 \mathrm{TW}$ of initially generated kinetic wind energy. Our simple momentum balance model and general circulation model simulations also reinforce points 4 and 5 .

In the general circulation model sensitivities with wind power extraction, we did find that model resolution affects the estimates. At a resolution of T21 and 10 vertical levels, a maximum of $2.1 \%(18 \mathrm{TW})$ of the control simulation total atmospheric dissipation rate of $838 \mathrm{TW}$ can be extracted as mechanical power from the control-region atmospheric boundary layer. Similarly, with sensitivity simulations at a resolution of T42 and 20 vertical levels, a maximum of 3.2\% ( $34 \mathrm{TW}$ ) of the control simulation total atmospheric dissipation rate of $1064 \mathrm{TW}$ can be extracted as mechanical power from the control-region atmospheric boundary layer. 

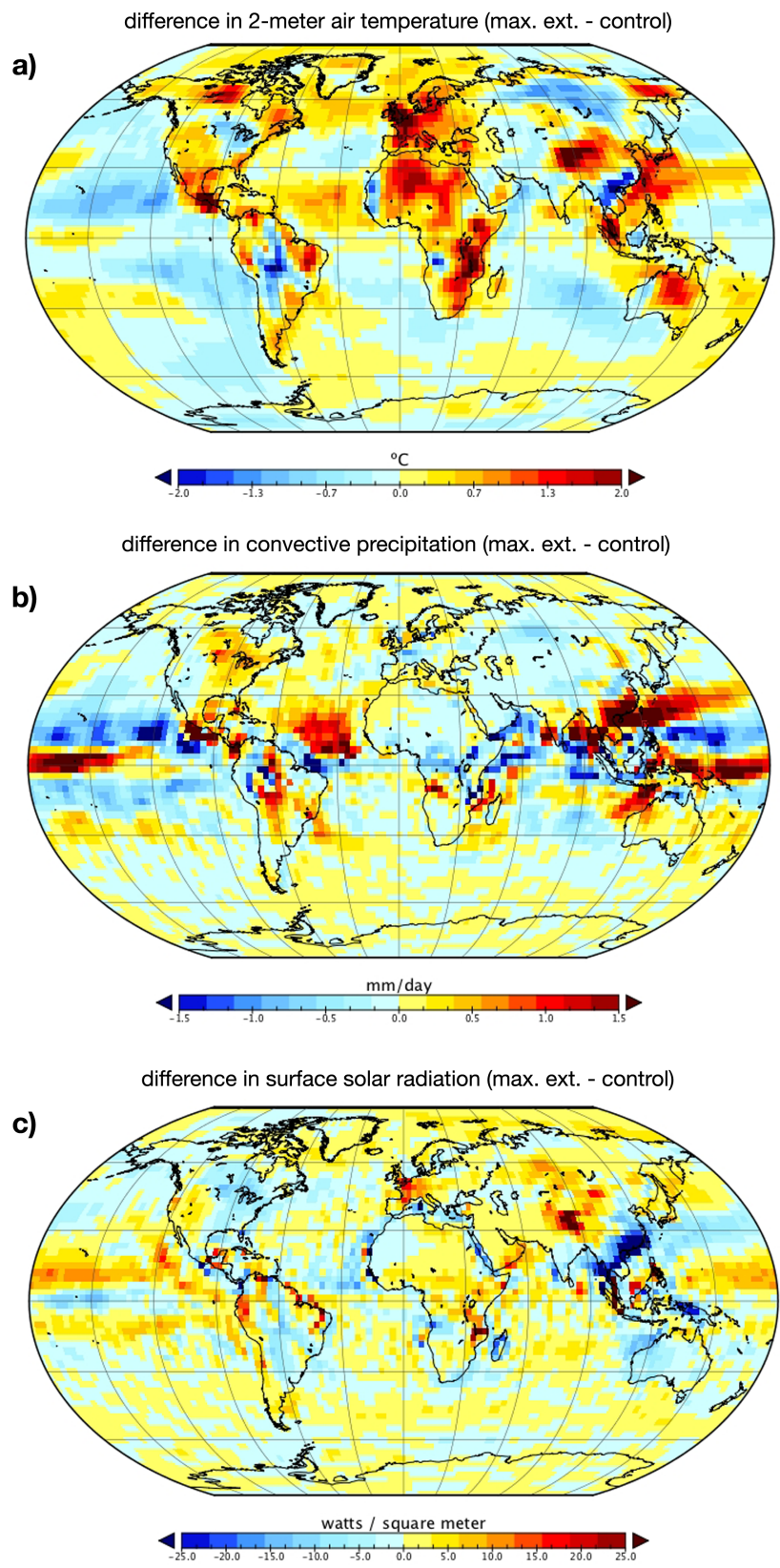

Fig. 9. The climatic consequences of large-scale wind power extraction is shown at T42 resolution with 20 vertical levels as a difference between the mean maximum extraction and mean control simulations for (a) 2-m air temperature, (b) convective precipitation, and (c) surface solar radiation.

Different model configurations do result in different dissipation rates. Assuming climatic steady-state, this difference in the dissipation rate also shows a difference in the modeled generation rate. Still, by relating the total atmospheric dissipation rate to extractable mechanical power, these estimates only vary by $\approx 1 \%$. A different general circulation model will certainly result in slightly different estimates, yet there is no obvious reason why other models should yield substantially different estimates in both maximized power extraction and the associated climatic consequences.

\subsection{Implications}

Given the variety of methodologies, we are confident that our estimates (18-68 TW) include the necessary complexity and processes to approximate the maximum extractable wind power over land within an order of magnitude. Adding additional complexity and/or processes may help to refine these estimates but will not drastically alter them. Nevertheless, this range of "top-down" estimates is up to $\approx 100$-times less than the common "bottom-up" engineering approach (Jacobson and Masters, 2001; Archer and Jacobson, 2003, 2005, 2007; Archer and Caldeira, 2009; Lu et al., 2009; Santa Maria and Jacobson, 2009; Jacobson and Archer, 2010a,b,c; Jacobson and Delucchi, 2010).

This alternative "bottom-up" engineering approach can be described as follows: using an extrapolated wind velocity to wind turbine hub height, a wind turbine power curve, air density, a modeled/measured/reanalysis-based wind velocity, a prescribed wind turbine density, and a geographic spatial area (e.g. land-only, land + nearshore, global), this approach attempts to estimate the extractable wind power. Note that in this approach, wind power is never removed from the global atmospheric system, leaving the global mean wind field and the wind field outside the wind turbine wake completely unaffected. This also suggests why more recent estimates continue to increase, as the "bottom-up" approach considers increased wind turbine height, rotor diameter, and aerodynamic efficiency to mimic engineering advancements (e.g. Archer and Jacobson, 2003, 2005, use 80-m hub height; Jacobson and Delucchi, 2010, use a 100-m hub height).

Following such an approach, on p. 816 of Santa Maria and Jacobson (2009), they state that "...should wind supply the world's energy needs [12 TW], this parameterization estimates energy loss in the lowest $1 \mathrm{~km}$ of the atmosphere to be $\approx 0.007 \%$." A simple translation of this statement suggests $>170000 \mathrm{TW}$ of wind derived electricity is continually available for extraction in the atmospheric boundary layer region. Similarly, using the same method but different assumptions, in Table 3 of Jacobson and Delucchi (2010), they estimate global extractable wind power at $100-\mathrm{m}=1700 \mathrm{TW}$. This "bottom-up" approach is also being used for estimating high-altitude wind power extractability, where on p. 307 of Archer and Caldeira (2009), they recently stated that "...total wind energy in the jet streams is roughly 100 times the global energy demand," assumed here to suggest an additional $\approx 1200-1700 \mathrm{TW}$ is available at higher altitudes, should the technology be developed and deployed effectively.

As shown, the "bottom-up" approach can exceed the $\approx 900$ TW simply by adding additional or larger wind turbines, thereby neglecting the current generation rate of 
kinetic wind energy in the total atmosphere (Peixoto and Oort, 1992) and exceeding the unattainable upper-limit for wind power extractability (Gustavson, 1979). Bergmann (2010) clearly identified this problem with the "bottom-up" approach used by Santa Maria and Jacobson (2009) and Jacobson and Archer (2010a) - it does not distinguish between the total instantaneous energy content of the atmosphere and the generation rate of energy into the atmospheric system.

This is primarily based on the "bottom-up" understanding of an atmosphere with wind turbines, where in response to Bergmann (2010), Jacobson and Archer (2010c) stated, "Energy loss occurs in the [wind turbine] wake, but not outside the [wind turbine] wake." Jacobson and Archer (2010a) further explain their approach when they state that, “...in the real atmosphere in the presence of wind turbines, $F_{\text {acc }}$ [generation rate of kinetic wind energy in the atmosphere] would increase by the rate of momentum extraction by wind turbines."

As previously also identified by Bergmann (2010), this is a perpetual motion machine. For a single wind turbine, the effect of energy removal from the total atmosphere is not relevant. With multiple turbines, the influence of the wind field on nearby and distant wind turbines begins to be relevant. Finally, when one strives to estimate the maximum extractable wind power from the atmospheric boundary layer over the global non-glaciated land surface, the limited generation rate becomes critically important (Gans et al. , 2010). Furthermore, the feedback of such a large perturbation to the atmosphere and its effect of decreasing the atmospheric generation rate also directly influences the estimates.

Our results show why the "top-down" approach must be utilized when estimating wind power at a large-scale - the generation rate of kinetic wind energy into the atmospheric system is critical. As such, wind power is a renewable but finite resource with associated fundamental limits to extraction (Gustavson, 1979). Utilizing wind power is also accompanied by unavoidable climatic consequences (Kirk-Davidoff , 2010). This study renews and reinforces these facts while constraining future large-scale wind power extractability estimates to realizable bounds.

\section{Conclusions}

We estimate that between 18-68 TW of mechanical wind power can be extracted from the atmospheric boundary layer over all non-glaciated land surfaces. Although wind power extraction from a single turbine has little effect on the global atmosphere, many more will influence atmospheric flow and reduce the large-scale extraction efficiency. Any extraction of momentum must also compete with the natural process of wind power dissipation by boundary layer turbulence.

Our study focuses on the rate of wind power generation in the climate system rather than previous near-surface estimates that focused on measured wind velocities and engineering limitations (e.g. Archer and Jacobson, 2005; Lu et al., 2009; Santa Maria and Jacobson, 2009). This consideration results in our estimate being significantly less than previous studies while also being independent of wind turbine size or layout.

Given that only 0.03 TW of wind-derived electricity was produced in 2008 (World Wind Energy Association, 2008), there is still substantial wind power development possible with relatively minor climatic impacts. However, future plans for large-scale wind power development must recognize the finite potential of the Earth system to generate kinetic wind energy. It has also been suggested that with increased carbon dioxide concentrations, the total atmospheric dissipation rate, and therefore its kinetic energy generation rate, will decrease (Lucarini et al., 2010; Hernández-Deckers and von Storch, 2010).

Future plans must accept that the human appropriation of wind power must be accompanied by a climatic effect and with large-scale deployment, will be associated with a decrease in the total atmospheric kinetic energy generation rate. Our estimation methods are certainly extreme, but they nevertheless provide critical understanding of the limits of wind power in the climate system and how it can serve human energy requirements.

Faced with the present-day global energy demand of 17 TW and a predicted change to 16-120 TW by 2100 (EIA, 2009; IPCC, 2007), extreme calculations such as this will provide the maximum power potentials and possible climatic effects of different forms of renewable energy sources planned to fulfill future human energy requirements. This in turn helps to prioritize which renewable energy resources are likely to be successful in meeting the future global human energy demand. More complex modeling studies can help refine our estimates and climatic impacts, but the presence of a maximum in wind power extractability and the associated climatic consequences from this extraction are fundamental.

Acknowledgement. The authors would like to thank C. L. Archer, J. C. Bergmann, D. B. Kirk-Davidoff, M. Z. Jacobson, V. Lucarini, and A. Speranza for their thoughts and comments on this manuscript along with the Biospheric Theory and Modeling Group, Chris Garrett, Raphael Proulx, Nathaniel Brunsell, and Kerry Hinds for discussions and constructive comments. The authors declare that they have no competing financial interests.

The service charges for this open access publication have been covered by the Max Planck Society.

Edited by: V. Lucarini 


\section{References}

Archer, C. L. and Caldeira, K.: Global assessment of high-altitude wind power, IEEE T. Energy Conver., 2, 307-319, 2009.

Archer, C. L. and Jacobson, M. Z.: Spatial and temporal distributions of U.S. winds and wind power at $80 \mathrm{~m} \mathrm{de}$ rived from measurements, J. Geophys. Res., 108(D9), 4289, doi:10.1029/2002JD002076, 2003.

Archer, C. L. and Jacobson, M. Z.: Evaluation of global wind power. J. Geophys. Res., 110, D12110, doi:10.1029/2004JD005462, 2005.

Archer, C. L. and Jacobson, M. Z.: Supplying baseload power and reducing transmission requirements by interconnecting wind farms, J. Appl. Meteorol., 46, 1701-1717, doi:10.1175/2007JAMC1538.1, 2007.

Barrie, D. B. and Kirk-Davidoff, D. B.: Weather response to a large wind turbine array, Atmos. Chem. Phys., 10, 769-775, doi:10.5194/acp-10-769-2010, 2010.

Bergmann, J. C.: Interactive comment on "Estimating maximum global land surface wind power extractability and associated climatic consequences" by L. M. Miller et al. (Earth Syst. Dynam. Discuss., 1, 169-189, doi:10.5194/esdd-1-169-2010, 2010) Earth Syst. Dynam. Discuss., 1, C96-C100, 2010.

Betz, A.: The maximum of theoretically available potential of wind by wind turbines (originally German), Z. Gesamte Turbinenwesen, Heft 26, 1920.

Calaf, M., Meneveau, C., and Meyers, J.: Large eddy simulation study of fully developed wind-turbine array boundary layers, Phys. Fluids, 22, 015110, doi:10.1063/1.3291077, 2010.

European Centre for Medium Range Forecasting: The ERA-40 archive, European Centre for Medium Range Forecasting, Reading, UK, 2004.

Energy Information Administration: International Energy Outlook 2009, United States Department of Energy - Energy Information Administration, www.eia.doe.gov/oiaf/ieo/index.html, last access: February 2011, Washington DC, USA, 2009.

Fraedrich, K., Jansen, H., Kirk, E., Luksch, U., and Lunkeit, F.: The planet simulator: towards a user friendly model, Meteorol. Z., 14, 299-304, 2005.

Gans, F., Miller, L. M., and Kleidon, A.: The problem of the second wind turbine - a note on a common but flawed wind power estimation method, Earth Syst. Dynam. Discuss., 1, 103-114, doi:10.5194/esdd-1-103-2010, 2010.

Garrett, C. and Cummins, P.: The efficiency of a turbine in a tidal channel, J. Fluid Mech., 588, 243-251, 2007.

Gustavson, M. R.: Limits to wind power utilization, Science, 204, 13-17, 1979.

Hernández-Deckers, D. and von Storch, J. S.: Energetic responses to increases in greenhouse gas concentrations, J. Climate, 23, 3874-3887, 2010.

IPCC, 2007: Climate Change 2007: The Physical Science Basis, Contribution of Working Group I to the Fourth Assessment Report of the Intergovernmental Panel on Climate Change, edited by: Solomon, S., Qin, D., Manning, M., Chen, Z., Marquis, M., Averyt, K. B., Tignor, M., and Miller, H. L., Chapter 3, Figure 3.5, Cambridge University Press, Cambridge, UK and New York, NY, USA.
Jacobson, M. and Archer, C. L.: Comment on Estimating maximum global land surface wind power extractability and associated climatic consequences, edited by: Miller, L. M., Gans, F., and Kleidon, A. (Earth Syst. Dynam. Discuss., 1, 169-189, doi:10.5194/esdd-1-169-2010, 2010), Earth Syst. Dynam. Discuss., 1, C84-C85, 2010a.

Jacobson, M. and Archer, C. L.: Interactive comment on "Estimating maximum global land surface wind power extractability and associated climatic consequences" by L. M. Miller et al. (Earth Syst. Dynam. Discuss., 1, 169-189, doi:10.5194/esdd1-169-2010, 2010) Earth Syst. Dynam. Discuss., 1, C101-C103, 2010 b.

Jacobson, M. and Archer, C. L.: Reply to D. B. Kirk-Davidoff (Earth Syst. Dynam. Discuss., 1, 169-189, doi:10.5194/esdd-1169-2010, 2010) Earth Syst. Dynam. Discuss., 1, C112, 2010 c.

Jacobson, M. Z. and Delucchi, M. A.: Providing all global energy with wind, water, and solar power, part 1: technologies, energy resources, quantities and areas of infrastructure, and materials, Energy Policy, doi:10.1016/j.enpol.2010.11.040, 2010.

Jacobson, M. Z. and Masters, G. M.: Exploiting wind versus coal, Science, 293, 5534, doi:10.1126/science.1063376, 2001.

Keith, D., DeCarolis, J., Denkenberger, D., Lenschow, D., Malyshev, S. L., Pacala, S., and Rasch, P.: The influence of large-scale wind power on global climate, P. Natl. Acad. Sci., 101, 1611516120, 2004.

Kirk-Davidoff, D. B.: Interactive comment on "Estimating maximum global land surface wind power extractability and associated climatic consequences" by L. M. Miller et al., (Earth Syst. Dynam. Discuss., 1, 169-189, doi:10.5194/esdd-1-1692010, 2010), Earth Syst. Dynam. Discuss., 1, C94-C95, 2010.

Kirk-Davidoff, D. and Keith, D.: On the climate impact of surface roughness anomalies, J. Atmos. Sci., 65, 2215-2234, 2008.

Kleidon, A.: Life, hierarchy, and the thermodynamic machinery of planet Earth, Phys. Life Rev., 7, 424-460, 2010.

Kleidon, A., Fraedrich, K., Kunz, T., and Lunkeit, F.: The atmospheric circulation and states of maximum entropy production, Geophys. Res. Lett., 30, 2223, 2003.

Kleidon, A., Fraedrich, K., Kirk, E., and Lunkeit, F.: Maximum entropy production and the strength of the boundary layer exchange in an atmospheric general circulation model, Geophys. Res. Lett., 33, L06706, doi:10.1029/2005GL025373, 2006.

Lanchester, F. W.: A contribution to the theory of propulsion and the screw propeller, Trans. Inst. Naval Archit. LVII., 98-116, 1915.

Lorenz, E.: Available potential energy and the maintenance of the general circulation, Tellus, 7, 271-281, 1955.

Lorenz, E.: Generation of available potential energy and the intensity of the global circulation, Dynamics of Climate, Pergamon Press, Oxford, UK, 86-92, 1960.

Lorenz, R., Lunine, J., Withers, P., and McKay, C.: Titan, Mars, and Earth: entropy production by latitudinal heat transport, Geophys. Res. Lett., 28, 415-418, 2001.

Lu, X., McElroy, M. B., and Kiviluoma, J.: Global potential for wind-generated electricity, P. Natl. Acad. Sci., 106, 1093310938, 2009.

Lucarini, V., Fraedrich, K., and Lunkeit, F.: Thermodynamics of climate change: generalized sensitivities, Atmos. Chem. Phys., 10, 9729-9737, doi:10.5194/acp-10-9729-2010, 2010. 
Lunkeit, F., Bšttinger, M., Fraedrich, K., Jansen, H., Kirk, E., Kleidon, A., and Luksch, U.: Planet simulator reference manual version 15.0, Meteorological Institute of the University of Hamburg, Hamburg, 2007.

Paltridge, G. W.: The steady-state format of global climate, Q. J. Roy. Meteorol. Soc., 104, 927-945, 1978.

Peixoto, J. P. and Oort, A. H.: Physics of climate, American Institute of Physics, Springer-Verlag, New York, USA, 1992.

Roy, S. B. and Pacala, S.: Can wind farms affect local meteorology, J. Geophys. Res., 109, D19101, doi:10.1029/2004JD004763 2004.
Santa Maria, M. R. V. and Jacobson, M. Z.: Investigating the effect of large wind farms on energy in the atmosphere, Energies, 2, 816-838, 2009.

Wang, C. and Prinn, R. G.: Potential climatic impacts and reliability of very large-scale wind farms, Atmos. Chem. Phys., 10, 2053 2061, doi:10.5194/acp-10-2053-2010, 2010.

World Wind Energy Report: World Wind Energy Association 2009, Bonn, Germany, 2008. 